\title{
COMPOSIÇÃO MINERAL DE FOSFATOS, CALCÁRIO E FARINHA DE OSSOS USADOS NA AGROPECUÁRIA BRASILEIRA
}

\author{
MINERAL COMPOSITION OF PHOSPHATES, LIMESTONE AND BONE MEAL USED IN \\ BRAZILIAN AGRICULTURE AND LIVESTOCK
}

\begin{abstract}
Avelar, A.C. ${ }^{1 A}$, W.M. Ferreira ${ }^{1 B}$, W. Brito ${ }^{2 A}$ e M.A.B.C. Menezes ${ }^{2 B}$
1'Departamento de Zootecnia. Escola de Veterinária da UFMG. Avenida Antonio Carlos, 6627. Campus Pampulha Belo Horizonte. Brasil. Aavelara.can@gmail.com; Bwaltermf@ufmg.br

${ }^{2}$ Centro de Desenvolvimento da Tecnologia Nuclear. Comissão Nacional de Energia Nuclear (CDTN/CNEN). Rua Mario Werneck, s/n. Campus Pampulha Belo Horizonte. Brasil. Abritow@cdtn.br; Bmenezes@cdtn.br
\end{abstract}

\section{PaLAVRAS ChaVE ADICIONAIS}

Fósforo. Cálcio. Micronutrientes. Solubilidade.

\section{RESUMO}

Este estudo teve como objetivo caracterizar os fosfatos, um calcário e uma farinha de ossos comumente usados na agropecuária brasileira. A solubilidade dos fosfatos foi determinada usando soluções de 2 e $10 \%$ de ácido cítrico. A farinha de ossos calcinada e o sal mineral bovino apresentaram baixas solubilidades. Diversas técnicas foram empregadas nas análises minerais: difratometria de raios-x, absorção atômica de forno de grafite, colorimetria, gravimetria e ativação neutrônica. Com exceção dos fosfato sulfato de amônio e monoamônico, vários fosfatos analisados, bem como a farinha de ossos, são fontes simultâneas de fósforo e cálcio. Muitos destes produtos são também fontes de outros elementos como S, Si, $\mathrm{Na}, \mathrm{Fe}, \mathrm{Zn}$ e Co.

\section{SUMMARY}

This study aimed to characterize the common phosphates, a bone meal and a limestone usually used in Brazilian agriculture and livestock. The solutions used to measure the solubility of phosphates were 2 and $10 \%$ citric acid. Calcinated bone meal and bovine mineral supplement presented very low solubilities. Many techniques were employed in the mineral analyses: X-ray diffractometry, atomic absorption with carbon furnace, colorimetric and gravimetric techniques and instrumental neutron activation. Except for limestone, monoammonium and ammonium sulfate

Recibido: 24-9-07. Aceptado: 17-1-08.

\author{
AdDitionAl KEYWORDS \\ Phosphorus. Calcium. Micronutrients. Solubility.
}

phosphate, many tested phosphates are simultaneously $\mathrm{P}$ and Ca sources. Many of these products are also sources of one or more elements such as $\mathrm{S}, \mathrm{Si}, \mathrm{Na}, \mathrm{Fe}, \mathrm{Zn}$ and $\mathrm{Co}$.

\section{INTRODUÇÃO}

A indústria brasileira de rocha fosfática (tabela I) está concentrada nos estados de Minas Gerais (regiões do Triângulo Mineiro e Alto Paranaíba), Goiás e São Paulo(DNPM, 2006).

O presente estudo tem como objetivo caracterizar o calcário, farinha de ossos (bovino) calcinada e os fosfatos disponíveis ao produtor rural sob os aspectos da solubilidade em ácido cítrico (2 e 10\%) e da concentração de vários macro e microelementos essenciais à saúde animal presentes nestes produtos.

\section{MATERIAL E MÉTODOS}

Os produtos analisados foram adquiridos no mercado de Uberlândia, Minas Gerais, um dos maiores centros do agronegócio brasileiro. Foram retiradas amostras de 1000 gramas de cada pacote comercial. Amostras representativas de 100 gramas 
Tabela I. Principais empresas produtoras de fosfatos no Brasil, e suas participações no mercado. (Major phosphate producers in Brazil, and their market sharing).

\begin{tabular}{lcc}
\hline Empresas & UF & P\% \\
\hline Fertilizantes fosfatados & MG & 31,49 \\
S/A fosfértil & GO & 29,94 \\
Ultrafertil S/A & MG, SP & 21,45 \\
Bunge fertilizantes S/A & GO & 14,52 \\
Copebrás Ltda & SP & 0,82 \\
Socal S/A & TO & 0,70 \\
Itafós mineração Ltda & & \\
Companhia Baiana de & BA & 0,69 \\
Pesquisa Mineral & BA & 0,40 \\
Galvani indústria comércio & & \\
\hline
\end{tabular}

UF: Unidade da federação onde ocorreu a comercialização ou consumo da produção bruta ou beneficiada. MG: Minas Gerais. GO: Goiás. SP: São Paulo. TO: Tocantins. BA: Bahia.

$P$ : Participação percentual da empresa no valor total da comercialização da produção (Fonte: DNPM, 2006).

foram separadas e moídas em moinho elétrico com o intuito de se obter uma granulometria de $0,063 \mathrm{~mm}$ (\#250 na escala Tyler mesh) em mais de $90 \%$ dos grãos. O fosfato foi homogeneizado e encaminhado para cada uma das análises consideradas a seguir: difratometria de raios-x pelo método do pó (fases cristalinas); gravimetria $\left(\mathrm{S}\right.$ e $\left.\mathrm{SiO}_{2}\right)$, fósforo $\left(\mathrm{P}_{2} \mathrm{O}_{5}\right)$ por colorimetria com fosfomolibdato (Cunnif, 1995). Na, Zn, Fe e Co pela técnica nuclear de análise por ativação neutrônica no reator nuclear IPR-R1 do CDTN/CNEN (Avelar et al., 2002) e Espectrofotometria de absorção atômica $(\mathrm{CaO})$. Os ensaios de solubilidade seguiram a literatura (Duarte et al., 2003).

\section{RESULTADOSEDISCUSSÃO}

Os resultados qualitativos (tabela II) obtidos pela análise de difratometria por raios-x pelo método do pó anteciparam os resultados quantitativos obtidos com o emprego de outras técnicas analíticas (tabelas III e IV).

Os fosfatos monoamônico e o fosfato sulfato de amônio apresentaram como estrutura cristalina (tabela II) predominante a bifosfammita $\left(\mathrm{NH}_{4} \mathrm{H}_{2} \mathrm{PO}_{4}\right)$; possuem baixa concentração de $\mathrm{Ca}$, uma vez que este elemento não está presente nesse cristal.

A concentração de fósforo presente no fosfato supersimples é a mais baixa entre todos os produtos analisados. Isto se deve ao fato que o supersimples tem a anidrita $\left(\mathrm{CaSO}_{4}\right)$ como estrutura cristalina majoritária, molécula onde não há a presença de fósforo; é notável a grande presença de enxofre (tabela IV) neste fosfato, S proveniente da anidrita. Outro fosfato que apresenta alta concentração de enxofre é o fosfato sulfato de amônio, que apresenta a mascagnita $\left(\left(\mathrm{NH}_{4}\right)_{2} \mathrm{SO}_{4}\right)$ como fase cristalina maior.

A legislação brasileira determina que os rótulos dos suplementos minerais mencionem a solubilidade do fósforo em ácido cítrico a 2\% (alta correlação entre o teste e o valor biológico de assimilação animal), relação 1:1, para as fontes de fósforos utilizadas nas misturas de minerais, sendo de $90 \%$ o valor mínimo aceitável. Duarte $e t$ al. (2003) recomendam que seja adotado o ácido cítrico na concentração de $10 \%$ como o extrator, pois este solubiliza acima de $80 \%$ do fósforo das fontes notadamente de média a alta biodisponibilidade e menos de $50 \%$ da fonte cujo fósforo é reconhecidamente de baixo valor biológico. Os dados de solubilidade são apresentados na tabela III. O sal mineral e a farinha de ossos não apresentaram solubilidade suficiente para serem usadas na nutrição animal.

O sal mineral bovino foi o produto com a maior concentração de Si. Análise qualitativa por difratrometria de raios-x mostrou uma grande presença de quartzo $\left(\mathrm{SiO}_{2}\right)$ como fase cristalina menor (entre $3 \mathrm{e}$ $10 \%$ do total de cristais). Valor elevado de $\mathrm{Si}$ foi encontrado na farinha de ossos, que também apresenta o quartzo $\left(\mathrm{SiO}_{2}\right)$ como 
COMPOSIÇÃO DE FOSFATOS, CALCÁRIO E FARINHA DE OSSOS USADOS EM BRASIL

Tabela II. Características minerais dos produtos comercializados no mercado brasileiro. (Mineral profile of Brazilian commercial phosphate products).

\begin{tabular}{|c|c|c|c|}
\hline Produto & Predominante $(c>30 \%)$ & $\begin{array}{l}\text { Fase Cristalina } \\
\text { Maior }(30 \%>c>10 \%)\end{array}$ & Menor $(10 \%>c>3 \%)$ \\
\hline F. Bicálcico & $\begin{array}{l}\text { Monetita } \\
\left(\mathrm{CaHPO}_{4}\right)\end{array}$ & - & $\begin{array}{l}\text { Anidrita }\left(\mathrm{CaSO}_{4}\right) \\
\text { Apatita } \\
\left(\mathrm{Ca}_{5}\left(\mathrm{PO}_{4}\right)_{3}(\mathrm{Cl}, \mathrm{F}, \mathrm{OH})\right) \\
\text { Gipso }\left(\mathrm{CaSO}_{4} \cdot 2 \mathrm{H}_{2} \mathrm{O}\right)\end{array}$ \\
\hline F. Monoamônico & $\begin{array}{l}\text { Bifosfammita } \\
\left(\mathrm{NH}_{4} \mathrm{H}_{2} \mathrm{PO}_{4}\right)\end{array}$ & - & $\left(\mathrm{NH}_{4}\right)_{2} \mathrm{H}_{2} \mathrm{P}_{2} \mathrm{O}_{5}$ \\
\hline F. Supersimples & Anidrita $\left(\mathrm{CaSO}_{4}\right)$ & \multicolumn{2}{|c|}{$\begin{array}{l}\text { Bifosfammita }\left(\mathrm{NH}_{4} \mathrm{H}_{2} \mathrm{PO}_{4}\right) \text { Bassanita } \\
\qquad\left(2 \mathrm{CaSO}_{4} \cdot \mathrm{H}_{2} \mathrm{O}\right)\end{array}$} \\
\hline F. Supertriplo & $\mathrm{Ca}\left(\mathrm{H}_{2} \mathrm{PO}_{4}\right) \cdot 2 \mathrm{H}_{2} \mathrm{O}$ & - & $\begin{array}{l}\text { Brushita } \\
\left(\mathrm{CaHPO}_{4} \cdot 2 \mathrm{H}_{2} \mathrm{O}\right) \\
\text { Anidrita }\left(\mathrm{CaSO}_{4}\right)\end{array}$ \\
\hline F. Sulfato amônio & $\begin{array}{l}\text { Bifosfammita } \\
\left(\mathrm{NH}_{4} \mathrm{H}_{2} \mathrm{PO}_{4}\right)\end{array}$ & $\begin{array}{l}\text { Mascagnita } \\
\left(\left(\mathrm{NH}_{4}\right)_{2} \mathrm{SO}_{4}\right)\end{array}$ & $\mathrm{N}_{2} \mathrm{H}_{6} \mathrm{SO}_{4}$ \\
\hline $\begin{array}{l}\text { Polifosfato de } \\
\text { amônio e cálcio }\end{array}$ & $\begin{array}{l}\text { Flatt's salt } \\
\left(\mathrm{NH}_{4} \mathrm{Ca}_{2} \mathrm{H}_{7}\left(\mathrm{PO}_{4}\right)_{4} \cdot 2 \mathrm{H}_{2} \mathrm{O}\right)\end{array}$ & $\begin{array}{l}\text { Bifosfammita } \\
\left(\mathrm{NH}_{4} \mathrm{H}_{2} \mathrm{PO}_{4}\right)\end{array}$ & $\begin{array}{l}\text { Apatita } \\
\left(\mathrm{Ca}_{5}\left(\mathrm{PO}_{4}\right)_{3}(\mathrm{Cl}, \mathrm{F}, \mathrm{OH})\right)\end{array}$ \\
\hline Sal mineral bovino & $\begin{array}{l}\text { Apatita } \\
\left(\mathrm{Ca}_{5}\left(\mathrm{PO}_{4}\right)_{3}(\mathrm{Cl}, \mathrm{F}, \mathrm{OH})\right)\end{array}$ & - & $\begin{array}{l}\quad \text { Quartzo }\left(\mathrm{SiO}_{2}\right) \\
\text { Calcita }\left(\mathrm{CaSO}_{4}\right) \\
\text { Dolomita }\left(\mathrm{CaMg}\left(\mathrm{CO}_{3}\right)_{2}\right)\end{array}$ \\
\hline Farinha de ossos & $\begin{array}{l}\text { Apatita } \\
\left(\mathrm{Ca}_{5}\left(\mathrm{PO}_{4}\right)_{3}(\mathrm{Cl}, \mathrm{F}, \mathrm{OH})\right)\end{array}$ & - & Quartzo $\left(\mathrm{SiO}_{2}\right)$ \\
\hline Calcário calcítico & $\mathrm{CaCO}_{3}($ Calcita $)$ & - & - \\
\hline
\end{tabular}

Tabela III. Concentrações de $\mathrm{P}, \mathrm{Ca}$, e $\mathrm{SiO}$ e solubilidade dos produtos em ácido cítrico a $2 \%$ e a $10 \%$ dos produtos analisados (dados em \%), $n=3$, matéria natural, todos resultados em (\%). ( $\mathrm{P}, \mathrm{Ca}$ and $\mathrm{SiO}_{2}$ concentrations, and $2 \%$ and $10 \%$ citiric acid solubility of analysed products, $\mathrm{n}=3$, natural basis, all data in \%).

\begin{tabular}{lrrrrr}
\hline & & & & \multicolumn{2}{c}{ Solubilidade ácido cítrico } \\
& $\mathrm{P}$ & $\mathrm{Ca}$ & \multicolumn{1}{c}{$\mathrm{SiO}_{2}$} & \multicolumn{1}{c}{$\%$} & \multicolumn{1}{c}{$10 \%$} \\
\hline F. bicálcico & $19,4 \pm 0,2$ & $28,0 \pm 0,3$ & $0,21 \pm 0,05$ & $91 \pm 2$ & $92 \pm 3$ \\
F. monoamônico & $22,3 \pm 0,2$ & $1,4 \pm 0,2$ & $0,26 \pm 0,05$ & $100 \pm 1$ & $100 \pm 1$ \\
F. supersimples & $7,8 \pm 0,1$ & $18,7 \pm 0,3$ & $1,01 \pm 0,10$ & $40 \pm 4$ & $37 \pm 4$ \\
F. supertriplo & $19,5 \pm 0,2$ & $15,0 \pm 0,2$ & $1,15 \pm 0,10$ & $97 \pm 1$ & $99 \pm 2$ \\
F. sulfato amônio & $10,6 \pm 0,1$ & $1,4 \pm 0,1$ & $0,40 \pm 0,05$ & $88 \pm 4$ & $80 \pm 4$ \\
Polifosfato & $19,6 \pm 0,2$ & $15,4 \pm 0,1$ & $2,07 \pm 0,10$ & $87 \pm 3$ & $92 \pm 3$ \\
Sal mineral bovino & $12,0 \pm 0,1$ & $33,1 \pm 0,5$ & $12,30 \pm 1,50$ & $10 \pm 4$ & $14 \pm 3$ \\
Farinha de ossos & $14,4 \pm 0,3$ & $36,7 \pm 0,4$ & $9,92 \pm 1,00$ & $23 \pm 4$ & $32 \pm 3$ \\
Calcário calcítico & $0,1 \pm 0,1$ & $37,2 \pm 0,5$ & $1,45 \pm 0,05$ & n.a. & n.a. \\
\hline
\end{tabular}


Tabela IV. Concentrações de Na, Zn, Fe, Co nos produtos analisados (dados em $\mathrm{mg}^{-\mathrm{g}^{-1}}$ ) e $\mathrm{S} \mathrm{em} \mathrm{( \% ).} \mathrm{(Na,} \mathrm{Zn,} \mathrm{Fe}$, Co concentrations (results in $\mathrm{mg}^{-\mathrm{g}^{-1}}$ ) and $\mathrm{S}$ concentration (\%) in the analysed products).

\begin{tabular}{lccccc}
\hline Produto & $\mathrm{Na}$ & $\mathrm{Zn}$ & $\mathrm{Fe}$ & Co & $\mathrm{S}$ \\
\hline F. bicálcico & $467 \pm 20$ & $44,5 \pm 5,0$ & $6620 \pm 312$ & $12,1 \pm 1,1$ & $0,20 \pm 0,04$ \\
F. monoamônico & $1230 \pm 50$ & $65,1 \pm 6,5$ & $13600 \pm 691$ & $24,8 \pm 2,8$ & $1,00 \pm 0,18$ \\
F. supersimples & $1840 \pm 62$ & $60,7 \pm 6,0$ & $<1000$ & $35,9 \pm 2,9$ & $13,1 \pm 1,4$ \\
F. supertriplo & $1883 \pm 65$ & $25,0 \pm 2,5$ & $19230 \pm 895$ & $28,7 \pm 2,1$ & $1,15 \pm 0,20$ \\
F. sulfato amônio & $3380 \pm 80$ & $12,0 \pm 1,0$ & $12500 \pm 608$ & $4,1 \pm 0,5$ & $10,0 \pm 1,4$ \\
Polifosfato & $2430 \pm 97$ & $47,0 \pm 4,5$ & $20400 \pm 916$ & $24,7 \pm 2,5$ & $1,80 \pm 0,40$ \\
Sal mineral bovino & $1100 \pm 48$ & $44,9 \pm 0,5$ & $12500 \pm 639$ & $14,6 \pm 1,5$ & $0,20 \pm 0,04$ \\
Farinha de ossos & $8650 \pm 198$ & $239,0 \pm 8,5$ & $12450 \pm 523$ & $0,7 \pm 0,2$ & $0,30 \pm 0,04$ \\
Calcário & $256 \pm 17$ & $6,1 \pm 0,5$ & $2713 \pm 185$ & $0,4 \pm 0,1$ & $0,30 \pm 0,04$ \\
\hline
\end{tabular}

fase cristalina menor. O Si possui a participação na formação dos ossos; porém o excesso de Si pode causar a formação de cálculo renal(NRC, 1980).

Os elevados valores de $\mathrm{Na}$ e $\mathrm{Zn}$ (tabela IV) encontrados na farinha de ossos são compatíveis com os valores da literatura em estudos com ossos humanos: $5600 \mathrm{ppm}$ a $10100 \mathrm{ppm}(\mathrm{Na})$ e $187 \mathrm{ppm}(\mathrm{Zn})$ (Iyengar et al., 1978).

\section{CONCLUSÕES}

Pode-se concluir que com exceção do calcário e dos fosfatos monoamônico e o

\section{BIBLIOGRAFIA}

Avelar, A.C., J.C. Veado and M.A.B.C. Menezes. 2002. Study of essential elements in cattle tissues from a tropical country using neutron activation analysis. Food Nutr. Bull., 23: 237-240.

Duarte, H.C., D.C. Graça, F.M.O. Borges and O.J. Di Paula. 2003. Comparison between in vitro methods to determine the bioavaiability of phosphorus. Arq. Bras. Med. Vet. Zoo., 55: 80-84.

DNPM. 2006. Diretoria de desenvolvimento e economia mineral. Departamento Nacional de Produção Mineral. 2006 Anuário Mineral Brasileiro. Governo Federal do Brasil. Brasília. 77 pp. fosfato sulfato de amônio, todos os fosfatos e a farinha de ossos testados são fontes binárias de fósforo e cálcio. Adicionalmente, os fosfatos supersimples e o fosfato sulfato de amônio são fontes de enxofre; a farinha de ossos e o fosfato sulfato de amônio são fontes de sódio; o polifosfato e o fostato supertriplo são as maiores fontes de $\mathrm{Fe}$ dentre os produtos testados.

Atenção especial deve ser dada às misturas domésticas como o sal mineral bovino analisado, que provavelmente foi formulado com um fosfato de rocha (apatita com alto teor de quartzo e baixa solubilidade) inadequado para misturas de uso.

Cunnif, P. 1995. Official methods of analysis of AOAC International. 16 ed. AOAC International. Arlington.

lyengar, G.V., W.E. Kollmer and H.J.M. Bowen. 1978. The elemental composition of human tissues and body fluids: a compilation of values for adults. E.U.A. Verlag. New York. USA. 151 pp. NRC. 1980. National Research Council. Subcommittee on mineral toxicity in animals committee on animal nutrition mineral tolerance of domestic animals. National Academy of Sciences. USA. $577 \mathrm{pp}$. 